\title{
In vitro pathogenicity of the fungi Beauveria bassiana and Lecanicillium lecanii at different temperatures against the whitefly, Bemisia tabaci (Genn.) (Hemiptera: Aleyrodidae)
}

\author{
Azhar Uddin Keerio ${ }^{1 * \dagger}$, Talha Nazir ${ }^{1 \dagger}$, Yusuf Ali Abdulle ${ }^{1}$, Ghulam Hussain Jatoi ${ }^{1,2}$, Muswar Ali Gadhi ${ }^{1}$,
} Tauqir Anwar ${ }^{3}$, Tum Sokea ${ }^{1}$ and Dewen Qiu ${ }^{1 *}$

\begin{abstract}
The whitefly, Bemisia tabaci (Genn.) (Hemiptera: Aleyrodidae), is one of the most damaging pests in field crops as well as in greenhouses. The present study aimed to evaluate the in vitro pathogenicity of 2 fungus strains of Beauveria bassiana (BB-72 and BB-252) and one strain of Lecanicillium lecanii (V-2) against the whitefly (B. tabaci) at 4 different temperature degrees $20,24,28$, and $32^{\circ} \mathrm{C}$, using a spray method. Three different bioassays were carried out comprised of conidial concentrations and filtrate of fungal strains, BB-72, BB-252 and V-2, and their binary combinations. The $1.5 \mathrm{ml}$ of fungal filtrate was used in filtrate bioassay for each strain of fungus. Three different

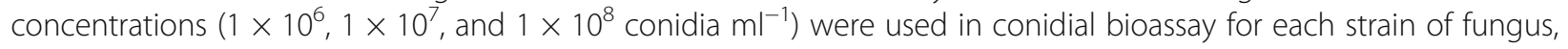
whereas in bioassay for binary combination ( $1 \mathrm{ml}$ conidia $+1 \mathrm{ml}$ filtrate) of BB-72 $\times$ BB-72, BB-252 $\times$ BB-252, and V2 $\times$ V2 were used for these strains of fungus. According to the outcomes, the maximum mortality against whiteflies was observed on 12th day post-treatment. In conidial bioassay, the maximum mortality of B. tabaci was observed in BB-72 isolate (84\%), BB-252 isolate (77\%), and V-2 isolate (67\%) at the highest concentration $\left(1 \times 10^{8} \mathrm{conidia} \mathrm{ml}^{-1}\right.$ ) at $24^{\circ} \mathrm{C}$, and minimum mortality was recorded in BB-72 isolate (33\%), BB-252 isolate (29\%), and V-2 isolate (19\%) at the lowest concentration $1 \times 10^{6}$ conidia $\mathrm{ml}^{-1}$ at $32^{\circ} \mathrm{C}$ on 12 th day post-treatment. Infiltrate bioassay, BB-72 isolate exhibited maximum mortality $(92 \%)$ at $24^{\circ} \mathrm{C}$, and $\mathrm{V}$-2 isolate showed minimum mortality (34\%) at $32^{\circ} \mathrm{C}$ on 12 th day post-treatment. Furthermore, in binary combination bioassay, the highest whitefly mortality was recorded in BB-72 $\times$ BB-72 isolate (87\%), BB-252 $\times$ BB-252 isolate (73\%), and V2 $\times$ V2 isolate $(65 \%)$ at $24^{\circ} \mathrm{C}$ and the lowest mortality in BB-72 $\times$ BB-72 isolate (57\%), BB-252 $\times$ BB-252 isolate (50\%), and V2 $\times$ V2 isolate (39\%) at $32^{\circ} \mathrm{C}$ on 12th day posttreatment. In all bioassays, the BB-72 isolate was the utmost virulent, and application of its filtrate was found to be the most impressive against $B$. tabaci.
\end{abstract}

Keywords: Entomopathogenic fungi, Beauveria bassiana, Lecanicillium lecanii, Virulence, Bemisia tabaci, Temperature degrees

\footnotetext{
*Correspondence: azharkeeryo@gmail.com; qiudewen@caas.cn

${ }^{\dagger}$ Azhar Uddin Keerio and Talha Nazir contributed equally to this work.

'State Key Laboratory for Biology of Plant Diseases and Insect Pests, Institute

of Plant Protection, Chinese Academy of Agricultural Sciences, Beijing

100081, People's Republic of China

Full list of author information is available at the end of the article
}

\section{Springer Open}

(c) The Author(s). 2020 Open Access This article is licensed under a Creative Commons Attribution 4.0 International License, which permits use, sharing, adaptation, distribution and reproduction in any medium or format, as long as you give appropriate credit to the original author(s) and the source, provide a link to the Creative Commons licence, and indicate if changes were made. The images or other third party material in this article are included in the article's Creative Commons licence, unless indicated otherwise in a credit line to the material. If material is not included in the article's Creative Commons licence and your intended use is not permitted by statutory regulation or exceeds the permitted use, you will need to obtain permission directly from the copyright holder. To view a copy of this licence, visit http://creativecommons.org/licenses/by/4.0/. 


\section{Background}

The whitefly, Bemisia tabaci (Genn.) (Hemiptera: Aleyrodidae), is one of the most destructive pest in the field crops as well as in greenhouses. It directly damages the crops causing heavy losses of the crops (Oliveira et al. 2001). Entomopathogenic fungi (EPF) have the ability to individually affect their host directly through the inward penetration in an insect (Lacey et al. 1996). Beauveria bassiana, V. lecanii, and Metarhizium anisopliae proved to be the most promising fungi in this respect (Wraight et al. 2007). For the control of whitefly, the entomopathogenic fungi have been used almost all around the world (Jackson et al. 2010). The potential strains best for utilization as pest management tools can be categorized into two groups: one group includes Hyphomycetes in Deuteromycotina and the other belongs to Entomophthorales (EPF) in Zygomycota (Feng 1998).

Very few of these EPF, viz., Nomuraea rileyi, Beauveria bassiana, Paecilomyces fumosoroseus, Metarhizium anisopliae, B. brongniartii, and Verticillium lecanii have been registered as products to control insect pests (Shah and Goettel 1999). B. tabaci showed resistance against the chemical insecticides such as nitenpyram, imidacloprid, acetamiprid, and pyrethroid (Horowitz et al. 2008). In china, many recent studies have revealed that most of the commonly available pesticides have lost their effectiveness in the control of whitefly (Wang et al. 2009). Therefore, the development of alternative sources of control is urgently needed. Biological control has now become key area of research in the management of $B$. tabaci over the past 2 decades (Cuthbertson et al. 2010). A number of microbial bio-pesticides based on entomopathogenic organisms like bacteria, nematodes, viruses, and fungi have been playing key roles in plant protection and were used against a broad range of insect pests (Majeed MZ et al. 2017). Entomopathogenic fungi like $M$. anisopliae, Isaria fumosorosea, B. bassiana, and $L$. lecanii proved to be impressive, target-specific, and environment-friendly biocontrol agents against several species of sucking insect pests (Cabanillas and Jones 2009). After germination of spores connected to the target insect's cuticle, fungal hyphae enter the body of the insect and cause death of host within a day (Mora et al. 2017). In addition, EPF have less or no residual activity or mammalian toxicity and are specific to the target pest, as well as there is less risk for developing resistance (Zimmermann 2007).

B. bassiana and L. Lecanii are the most studied EPF and known as a virulent biocontrol agent of a wide range of forest, field crops, and green house pests. These entomopathogens were equally effective in desert, agricultural, and forest habitats (Annamalai et al. 2016 and Dogan et al. 2017). Lately, (Nazir et al. 2019) demonstrated the toxicity of filtrates and conidia derived from different isolates of $L$. lecanii and $B$. bassiana against the aphid species, Myzus persicae (Sulz.).

The strains of both the entomopathogens can be easily isolated from the infected soil dwelling pests or from vegetation pests (Freed et al. 2011). As with other organisms, the growth rate of EPF varies by temperature. They are usually cultured nearby $25^{\circ} \mathrm{C}$, even depending on the strain in a single species (Sato 1993). The aim of the present study was to assess the pathogenicity and virulence of EPF, i.e., L. lecanii and B. bassiana against $B$. tabaci under controlled environmental conditions.

\section{Materials and methods}

\section{Whitefly stock culture}

Bemisia tabaci individuals were collected from the seedlings of tomato (Solanum lycopersicum) grown in the greenhouse at Chinese Academy of Agricultural Sciences (CAAS) Beijing, China. The population of whitefly was reared on the seedlings of same tomato grown in pots kept in cages at $25 \pm 2{ }^{\circ} \mathrm{C}$ and $5060 \%$ $\mathrm{RH}$ with photoperiod of $16: 8 \mathrm{~h}$ light:dark (L:D). In the entire study period, the plants were replaced weekly with new ones.

\section{Effect of temperature on fungus virulence against Bemisia tabaci}

Evaluation of the role of temperature, the pathogenicity bioassays of $B$. bassiana and L. lecanii against the nymphs of whitely, was carried out at $20,24,28$, and $32{ }^{\circ} \mathrm{C}$.

\section{Fungal isolates}

Two isolates of B. bassiana, namely, BB-72 and BB-252, and one isolate of L. lecanii, V-2 (Table 1), were cultured on potato dextrose agar (PDA) medium (agar 20 $\mathrm{g} / \mathrm{l}$., dextrose $20 \mathrm{~g} / \mathrm{l}$, and potatoes $200 \mathrm{~g} / \mathrm{l}$ ) plates and incubated at $24 \pm 2{ }^{\circ} \mathrm{C}$ in dark for 20-25 days.

\section{Conidial suspensions}

The conidia were harvested from 25 days of fungal culture plates using $\mathrm{ddH}_{2} \mathrm{O}$ with $0.01 \%$ Tween $80^{\circ}$ (Sigma-Aldrich, Saint Louis, MO, USA). The suspensions of conidia were collected and then filtered by Miracloth (EMD Milipore Corp., Billerica, MA, USA). Neubauer hemocytometer (Brand $\mathrm{GmbH}$, Wertheim, Germany) was used to adjust the conidial concentrations at $1 \times 10^{6}, 1 \times 10^{7}$, and $1 \times 10^{8}$ conidia $\mathrm{ml}^{-1}$. Before doing bioassays against whitefly, the conidial viability test was carried out, according to the methods described by (Hywel-Jones and Gillespie 1990).

\section{Fungal filtrate}

Adamek's liquid medium (40 g yeast extract (Difco, Detroit, MI, USA), $40 \mathrm{~g}$ dextrose and $30 \mathrm{~g}$ corn steep liquor (SigmaAldrich, Saint Louis, MO, USA), was used for primary 
Table 1 Studied fungal isolates, code of strain, source, and geographical area of Beauveria bassiana and Lecanicillium lecanii strains

\begin{tabular}{llll}
\hline Fungal isolates & Code of strains & Source & Geographical area \\
\hline B. bassiana 72 & BB-72 & Green peach aphid & Vladivostok (Russia) \\
B. bassiana 252 & B -252 & Green peach aphid & Vladivostok (Russia) \\
L. lecanni 2 & V-2 & Whitefly & Moscow (Russia) \\
\hline
\end{tabular}

culture of fungal filtrate by adding $4 \mathrm{ml}$ of conidial suspension into $100 \mathrm{ml}$ of medium for all the strains of fungi. Cultures were incubated for $72 \mathrm{~h}$ at $150 \mathrm{rpm}$, and then for secondary culture, $5 \mathrm{ml}$ from primary culture was added into $500 \mathrm{ml}$ of Adamek's liquid medium and incubated at $26^{\circ} \mathrm{C}$ and $150 \mathrm{rpm}$ for 6 days for each strain. The samples were then centrifuged at $12000 \mathrm{rpm}$ and $4{ }^{\circ} \mathrm{C}$ for $30 \mathrm{~min}$. After that, the supernatant was filtered through $0.45 \mu \mathrm{m}$ pore size filter (Millipore Corp., Billerica, MA, USA) to get filtrate, and $\mathrm{pH}$ was sustained at 6 .

\section{Pathogenicity bioassays}

To evaluate the efficacy of filtrate, conidia, and binary combinations, different bioassays were carried out. For binary combination bioassays (conidia + filtrate), $1 \mathrm{ml}$ of the high-

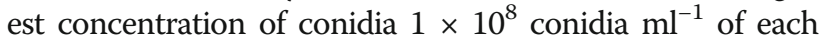
fungal isolate was combined with $1 \mathrm{ml}$ filtrate of the same fungal isolate. The combinations were BB-72 $\times$ BB-72, BB$252 \times$ BB- 252, and V2 $\times$ V2. For all treatments ,the 90$\mathrm{mm}$ Petri dishes were used with a skinny layer of $1.5 \%$ agar, and $50 \mathrm{~mm}$ diameter of leaf discs of tomato was placed in Petri dishes. In the control treatment, the leaf discs were sprayed only by $0.01 \%$ Tween $80^{\circ}$. Ten apterous adult of $B$. tabaci were released on the leaf discs at each Petri dish, and $1.5 \mathrm{ml}$ sample of each of the treatments was sprayed on B. tabaci with the help of small sprayer and then these Petri dishes were incubated at $20,24,28$, and $32^{\circ} \mathrm{C}$ and $50-60 \%$ $\mathrm{RH}$ with photoperiod of 16:8 h light:dark (L:D) for 12 days. Ten replications of each treatment were used. B. tabaci mortality was recorded after $3,6,9$, and 12 days posttreatment.

\section{Data analysis}

Virulence of the two strains of B. bassiana and one strain of $L$. lecanii as filtrate, conidia, and binary combination (conidia + filtrate) were analyzed, using factorial analysis of the variance (Statistix software (version 8.1) (Tallahassee, FL)). Comparisons of the treatment means were performed using Fischer's least significant difference (LSD) test at $a=0.05$.

Table 2 Factorial analysis of variance of mortality of Bemisia tabaci bioassay with the conidia of two strains of Beauveria bassiana and one strain of Lecanicillium lecanii

\begin{tabular}{|c|c|c|c|c|c|}
\hline Source & DF & SS & MS & $\boldsymbol{F}$ value & $\boldsymbol{p}$ value \\
\hline Fungus & 2 & 116.3 & 58.17 & 101.3 & $\leq 0.001$ \\
\hline Days & 3 & 2784.8 & 928.27 & 1616.3 & $\leq 0.001$ \\
\hline Temperature & 3 & 323.4 & 107.81 & 187.7 & $\leq 0.001$ \\
\hline Concentration & 3 & 2819.0 & 939.69 & 1636.2 & $\leq 0.001$ \\
\hline Fungus $\times$ temperature & 6 & 139.1 & 23.18 & 40.3 & $\leq 0.001$ \\
\hline Fungus $\times$ days & 6 & 6.4 & 1.06 & 1.8 & 0.0843 \\
\hline Fungus $\times$ concentration & 6 & 46.1 & 7.69 & 13.4 & $\leq 0.001$ \\
\hline Temperature $\times$ days & 9 & 110.7 & 12.30 & 21.4 & $\leq 0.001$ \\
\hline Temperature $\times$ concentration & 9 & 103.9 & 11.55 & 20.1 & $\leq 0.001$ \\
\hline Days $\times$ concentration & 9 & 986.9 & 109.65 & 190.9 & $\leq 0.001$ \\
\hline Fungus $\times$ temperature $\times$ days & 18 & 113.5 & 6.30 & 10.9 & $\leq 0.001$ \\
\hline Fungus $\times$ temperature $\times$ concentration & 18 & 50.7 & 2.81 & 4.9 & $\leq 0.001$ \\
\hline Fungus $\times$ days $\times$ concentration & 18 & 12.5 & 0.69 & 1.2 & 0.2386 \\
\hline Temperature $\times$ days $\times$ concentration & 27 & 51.9 & 1.92 & 3.3 & $\leq 0.001$ \\
\hline Fungus $\times$ temperature $\times$ days $\times$ concentration & 54 & 51.6 & 0.95 & 1.6 & 0.0019 \\
\hline Error & 1728 & 992.4 & 0.5 & & \\
\hline Total & 1919 & 8709.9 & & & \\
\hline $\mathrm{CV} / \mathrm{GM}$ & \multicolumn{5}{|c|}{$35.06 / 2.16$} \\
\hline
\end{tabular}

${ }^{*} p<0.001$ (highly significant) four-way factorial analysis of variance (ANOVA) at $a=0.05$. DF degree of freedom, SS sum of squares, MS mean sum of squares, $F$ Fstatistic, CV coefficient of variation, GM grand mean 


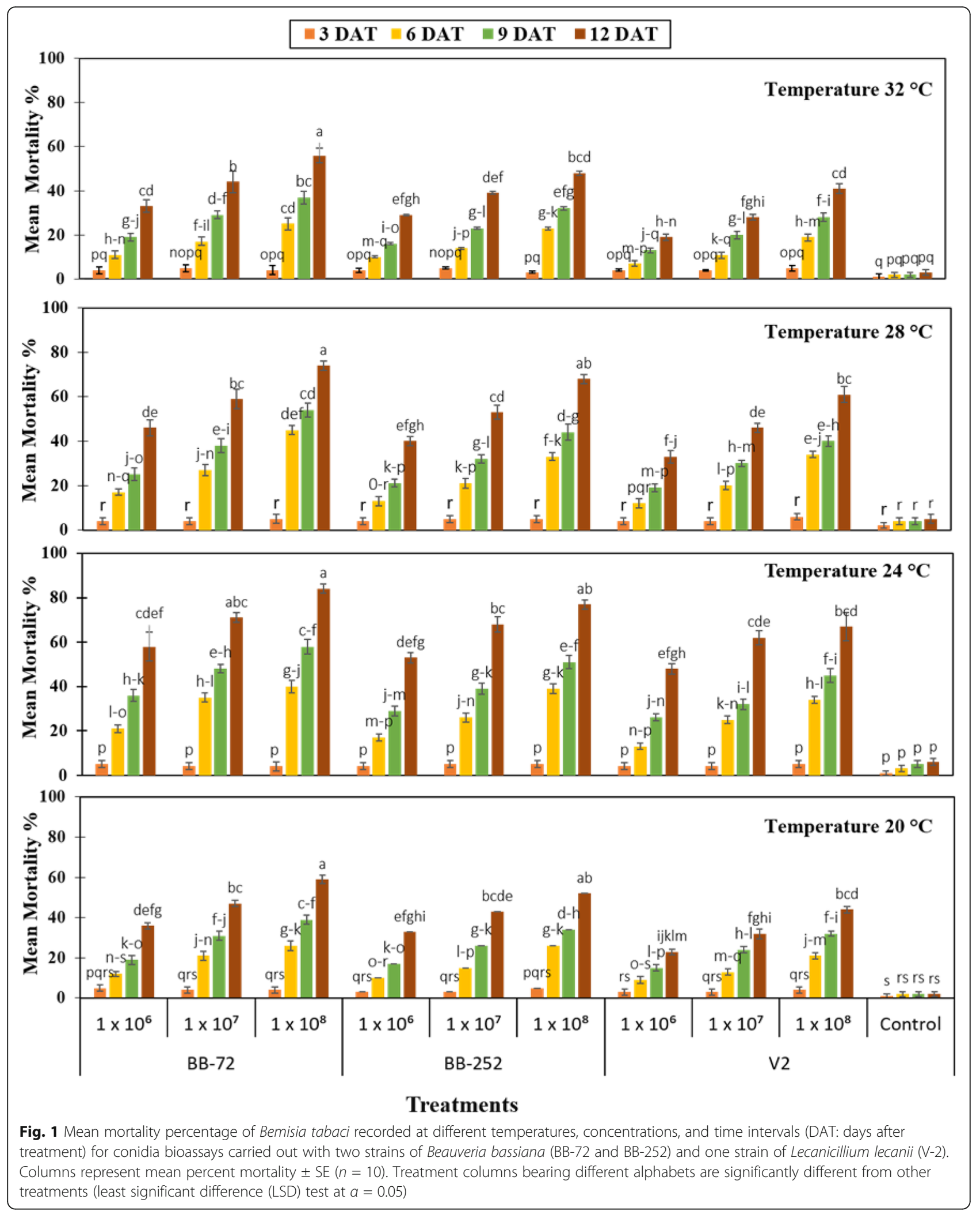




\section{Result and discussion}

\section{Conidial virulence}

In conidial bioassay, the results showed that all the isolates tested revealed significant mortality of whitefly individuals $(F=101.30, p<0.001$; Table 2$)$. Moreover, the factorial analysis of variance exhibited that there was a significant effect of temperature levels, time intervals, concentrations, and their interaction on whitefly mortality rate (Table 2 ). The maximum mortality of $B$. tabacii was observed in BB-72 isolate (84\%), BB-252 isolate

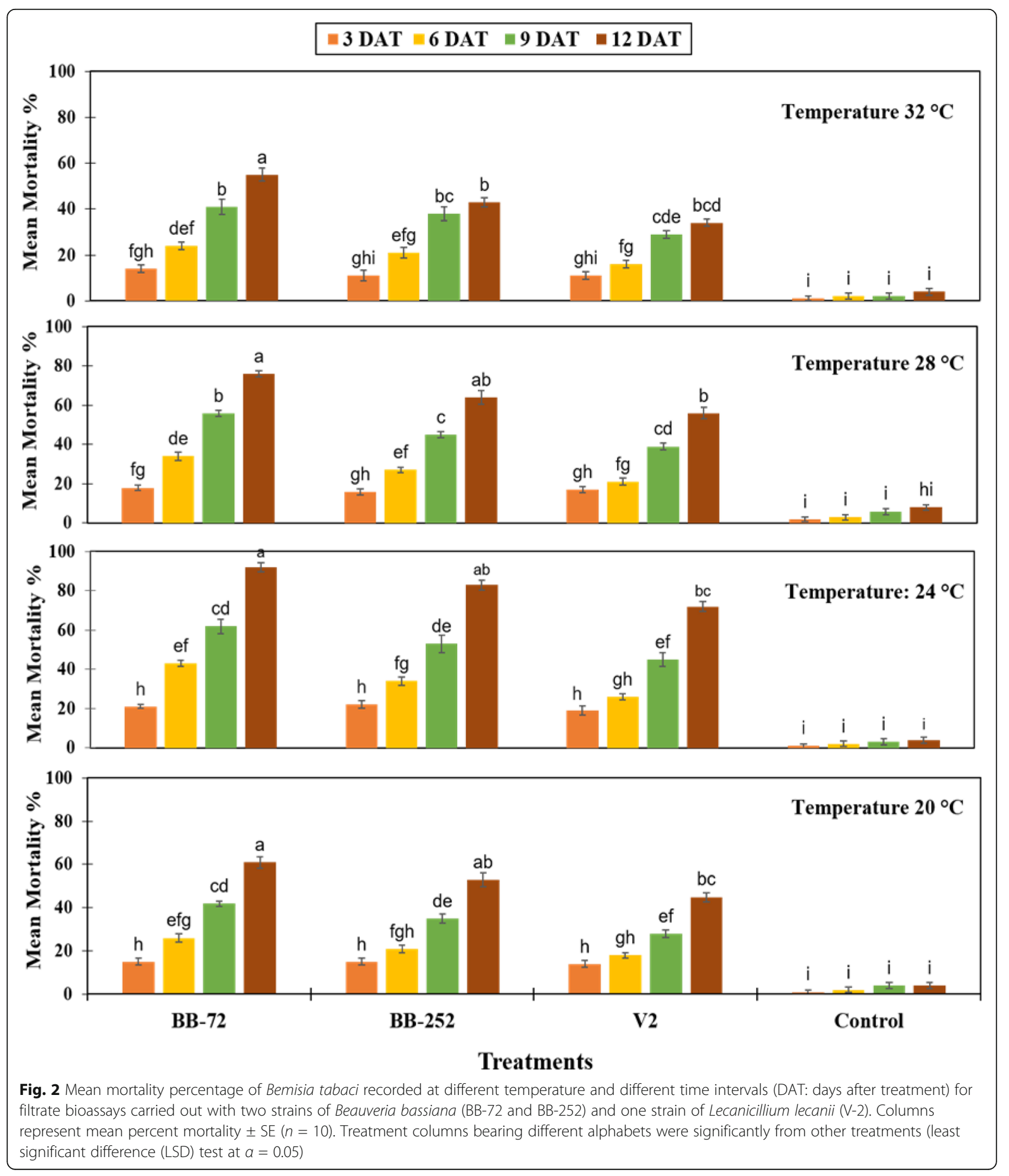


(77\%), and V-2 isolate (67\%) at the highest concentration $1 \times 10^{8}$ conidia $\mathrm{ml}^{-1}$, and low mortalities were recorded at the lowest concentration $1 \times 10^{6}$ conidia $\mathrm{ml}^{-1}$ on 12 th day of post-treatment at $24{ }^{\circ} \mathrm{C}$ (Fig. 1). The minimum mortality of whitefly was recorded by BB-72 isolate (33\%), BB-252 isolate (29\%), and V-2 isolate (19\%) at the lowest concentration $1 \times 10^{6}$ conidia $\mathrm{ml}^{-1}$ on 12 th day of post-treatment at $32{ }^{\circ} \mathrm{C}$ (Fig. 1). The mean mortality at the highest concentration $1 \times 10^{8}$ conidia $\mathrm{ml}^{-1}$ in BB72 isolate (74\%), BB-252 isolate (68\%), and V-2 isolate $(61 \%)$ and at the lowest concentration $1 \times 10^{6}$ conidia $\mathrm{ml}^{-1}$ in BB-72 isolate (46\%), BB-252 isolate (40\%), and $\mathrm{V}-2$ isolate $(33 \%)$ was recorded on 12 th day of posttreatment at $28{ }^{\circ} \mathrm{C}$ (Fig. 2). The mean mortality was at the lowest concentration $1 \times 10^{6}$ conidia $\mathrm{ml}^{-1}$ in BB-72 isolate (36\%), BB-252 isolate (33\%), and $\mathrm{V}-2$ isolate (23\%), and at the highest concentration $1 \times 10^{8}$ conidia $\mathrm{ml}^{-1}$ in BB-72 isolate (59\%), BB-252 isolate (52\%), and $\mathrm{V}-2$ isolate $(44 \%)$ was recorded on 12 th day of posttreatment at $20^{\circ} \mathrm{C}$ (Fig. 1). The mean mortality of $B$. tabaci in the control Petri-plates was noticeably low (6\%) after 12th day post-treatment.

\section{Filtrate pathogenicity}

Results of the filtrate bioassay showed that the mortality percentages of whitefly by all isolates of the fungus were more than those of the conidial treatments. The fungal filtrate, observation time, temperature, and their interactions had significant effects on B. tabaci mortality (Table 3). Maximum mortality of B. tabaci was observed in BB-72 isolate (92\%), BB-252 isolate (83\%), and V-2 isolate (72\%) on 12th day of treatment at $24^{\circ} \mathrm{C}$. Minimum mortality was observed in BB-72 isolate (55\%), BB-252 isolate (43\%), and V-2 isolate $(34 \%)$ on 12 th day of treatment at $32{ }^{\circ} \mathrm{C}$. On the other hand, the mean mortality of BB-72 isolate (76\%), BB-252 isolate (64\%), and V-2 isolate (56\%) was on 12th day of treatment at $28^{\circ} \mathrm{C}$, while the mean mortality of $\mathrm{BB}-72$ isolate (61\%), BB-252 isolate (53\%), and $\mathrm{V}-2$ isolate $(45 \%)$ was on 12 th day of treatment at $20^{\circ} \mathrm{C}$ (Fig. 2).

\section{Binary combinations}

The bioassay was carried out with the binary combinations of (conidia + filtrate) of two strains of B. bassiana (BB-72 and BB-252) and one strain of L. lecanii (V-2), and they showed significant control of B. tabaci. On B. tabaci mortality, the binary combinations (conidia + filtrate), observation time, temperature, and their interactions had significant effects (Table 4). Significant and the highest white fly mortality was recorded in BB-12th day of treatment at $24{ }^{\circ} \mathrm{C}$, while the lowest white fly mortality was recorded in BB-72 $\times$ BB-72 isolate (57\%), BB-252 $\times$ BB-252 isolate (50\%), and V2 $\times$ V2 isolate $(39 \%)$ on 12 th day of treatment at $32{ }^{\circ} \mathrm{C}$. The mean mortality of BB-72 $\times$ BB-72 isolate (74\%), BB-252 $\times$ BB-252 isolate
Table 3 Factorial analysis of variance of mortality of Bemisia tabaci bioassay with the filtrate of two strains of Beauveria bassiana and one strain of Lecanicillium lecanii

\begin{tabular}{llllll}
\hline Source & DF & SS & MS & $\boldsymbol{F}$ value & $\boldsymbol{p}$ value \\
\hline Fungus & 3 & 1472.2 & 490.7 & 1114.2 & $\leq 0.001$ \\
Days & 3 & 097.0 & 365.6 & 830.2 & $\leq 0.001$ \\
Temperature & 3 & 276.2 & 92.0 & 209.0 & $\leq 0.001$ \\
Fungus $\times$ days & 9 & 317.4 & 35.2 & 80.0 & $\leq 0.001$ \\
Fungus $\times$ temperature & 9 & 90.4 & 10.0 & 22.8 & $\leq 0.001$ \\
Days $\times$ temperature & 9 & 90.3 & 10.0 & 22.7 & $\leq 0.001$ \\
Fungus $\times$ days $\times$ temperature & 27 & 31.5 & 1.1 & 2.6 & $\leq 0.001$ \\
Error & 576 & 253.7 & 0.4 & & \\
Total & 639 & 629.1 & & & \\
CV/GM & $23.43 / 2.83$ & & & \\
\hline$p<0.001($ highly & &
\end{tabular}

${ }^{*} p<0.001$ (highly significant) three-way factorial analysis of variance (ANOVA) at $a=0.05$. DF degree of freedom, SS sum of squares, MS mean sum of squares, $F$ F-statistic, CV coefficient of variation, $G M$ grand mean

$(60 \%)$, and V2 $\times$ V2 isolate $(51 \%)$ on 12 th day of treatment at $28{ }^{\circ} \mathrm{C}$, whereas the mean mortality of BB-72 $\times$ BB-72 isolate (64\%), BB-252 $\times$ BB-252 isolate $(50 \%)$, and $\mathrm{V} 2 \times \mathrm{V} 2$ isolate $(50 \%)$ on 12 th day of treatment at $20{ }^{\circ} \mathrm{C}$ (Fig. 3).

The development of biocontrol research tools based on entomopathogenic fungi with improved efficacy against the target pests is one of the key areas of biological control research. Several insect pests have been controlled by the different entomopathogenic fungal strains (Yun et al. 2017).

Obtained results are in accordance with the previous studies describing the effectiveness of different isolates of $L$. lecanii and B. bassiana against sucking insect pests (Hesketh et al. 2008). In all bioassays, the

Table 4 Factorial analysis of variance of mortality of Bemisia tabaci bioassayed with the binary combinations (conidia + filtrate) of two strains of Beauveria bassiana and one strain of Lecanicillium lecanii

\begin{tabular}{llllll}
\hline Source & DF & SS & MS & $\boldsymbol{F}$ value & $\boldsymbol{p}$ value \\
\hline Fungus & 3 & 1333.99 & 444.663 & 950.02 & $\leq 0.001$ \\
Days & 3 & 1196.14 & 398.712 & 851.85 & $\leq 0.001$ \\
Temperature & 3 & 151.91 & 50.638 & 108.19 & $\leq 0.001$ \\
Fungus $\times$ days & 9 & 363.33 & 40.369 & 86.25 & $\leq 0.001$ \\
Fungus $\times$ temperature & 9 & 53.65 & 5.961 & 12.74 & $\leq 0.001$ \\
Days $\times$ temperature & 9 & 28.70 & 3.189 & 6.81 & $\leq 0.001$ \\
Fungus $\times$ days $\times$ temperature & 27 & 18.69 & 0.692 & 1.48 & 0.0578 \\
Error & 576 & 269.60 & 0.468 & & \\
Total & 639 & 3416.00 & & & \\
CV/GM & $24.88 / 2.75$ & & & \\
\hline
\end{tabular}

${ }^{*} p<0.001$ (highly significant) three-way factorial analysis of variance (ANOVA) at $a=0.05$. DF degree of freedom, SS sum of squares, MS mean sum of squares, F F-statistic, CV coefficient of variation, GM grand mean 


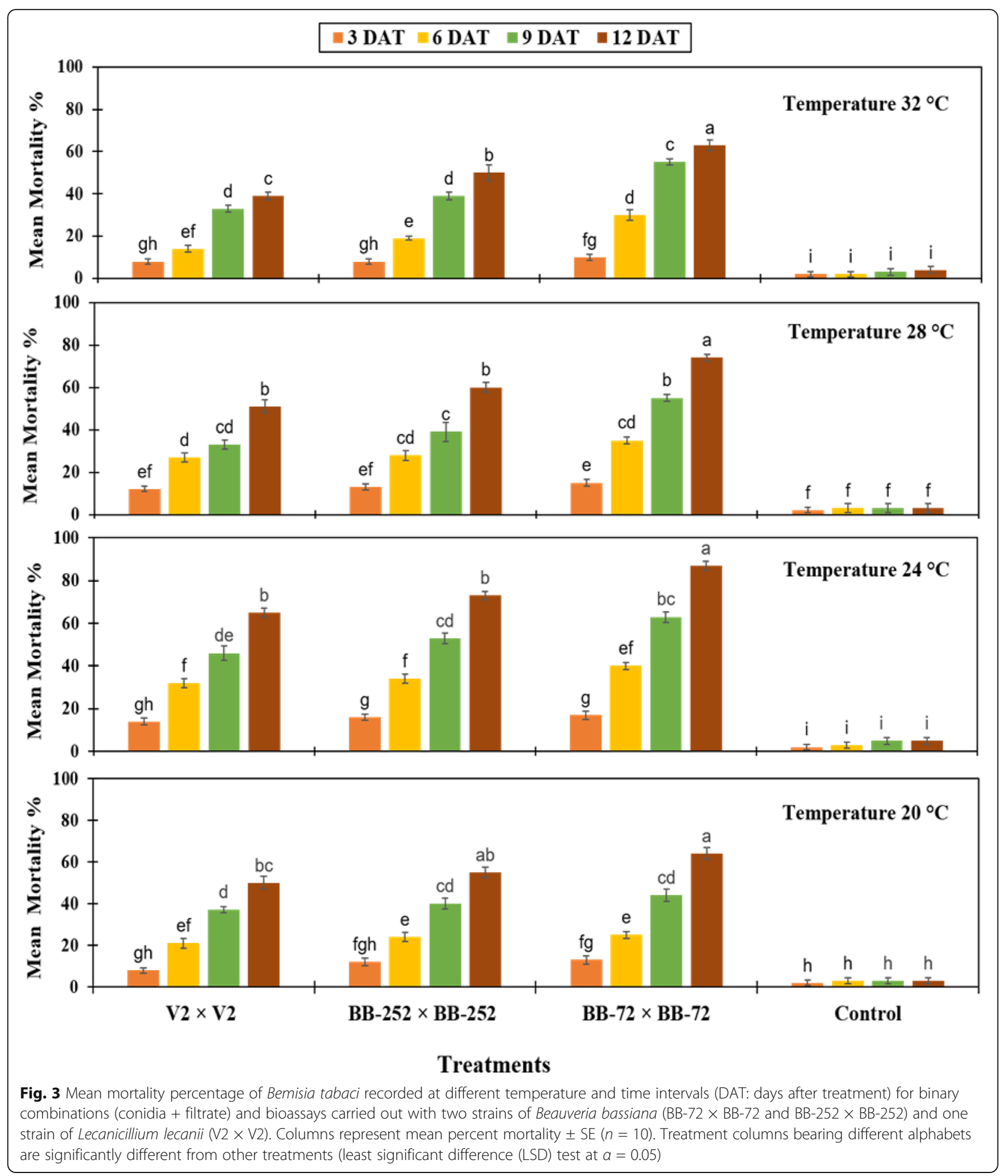

mortality of whiteflies was dependent on temperature, time, and concentration, and it increased by increasing the concentrations of conidia and time after application at optimum temperature. Mortality of 92, 83 and $72 \%$ was recorded after 12 days of filtrate application of BB-72, BB-252, and V-2 isolate, in that order, while 84,77 , and $67 \%$ mortality of whiteflies was found after 12 days at the highest concentration $1 \times 10^{8}$ conidia ml ${ }^{-1}$ of BB-72, BB-252, and V-2 isolate at $24^{\circ} \mathrm{C}$. Another experiment was carried out and reported 87, 
73 , and $65 \%$ mortality of whiteflies after 12 days through binary combination of conidia + filtrate of BB-72 $\times$ BB-72, BB-252 $\times$ BB-252, and V2 $\times$ V2 isolates. These results are in accordance with (Wraight et al. 2000) who reported that B. bassiana caused up to $97 \%$ mortality, and V. lecanii showed $100 \%$ mortality of Chilo partellus. Obtained results are in accordance with (Halimona and Jankevica 2011), who tested various concentrations of $B$. bassiana against $A$. fabae and Metopeurum fuscoviride and found that the highest concentration of conidia $1 \times 108 \mathrm{ml}^{-1}$ showed maximum mortality after 7 th day of application.

The percentage of mortality was affected by temperature, conidial concentration, and exposure time (Ansari et al. 2004). B. bassiana showed a great effect on the B. tabaci and Aphis craccivora infesting cucumber (Maniania 1991). The $V$. lecanii showed high mortality in early stages of B. tabaci and less mortality in old instars (Zaki 1998). EPF showed a good control of $B$. tabaci (Abdel-Raheem et al. 2016). The filtrate application was more effective to control the insect pests than the conidial application mainly in the case of short life cycled insects. There may be a possible cause that the less attachment of conidia to the insect cuticle as compared to huge infiltration of filtrates (Hanan et al. 2020a b).

Concerning the combined application obtained results is identical to (Yun et al. 2017) who studied the double behavior of EPF B. bassiana and $M$. anisopliae against $M$. persicae and B. cinerea and witnessed that the usage of filtrate with blastospores provided the maximum mortality of $M$. persicae. Furthermore, the mortality percentage was near to the combination of filtrates with blastospores; however, the combination of conidia and filtrate gave the minimum mortality as compared to filtrate application. So, it is clear that the fungal filtrate application had extreme virulence efficiency. Moreover, EPF are considered safe and environmentally friendly than the chemical pesticides (Goettel and Jaronski 1997); so, they are suggested as a control agent against destructive insect pests, like whitefly $B$. tabaci.

\section{Conclusion}

The in vitro study exhibited the efficiency of 2 strains of $B$. bassiana and one strain of L. lecanii against B. tabaci. L. lecanii showed lower mortality than both strains of $B$. bassiana either singly or in binary combinations (conidia + filtrate) of same strain at optimum temperature. The application of filtrate was utmost appropriate material to control B. tabaci. The binary combination of filtrate + its conidia had some irreconcilable effect and cannot effectively be used to control $B$. tabaci. Further studies are still needed to assess the role of EPF against B. tabaci, especially under field conditions.

\section{Abbreviations}

PDA: Potato dextrose agar; $\mathrm{ddH}_{2} \mathrm{O}$ : Double-distilled water; L:D: Light:dark; DF: Degree of freedom; $\mu \mathrm{m}$ : Micrometer; ml: Milliliter; $\mathrm{pH}$ : Potential of hydrogen; Rpm: Revolutions per minute; DAT: Days after treatment; SS: Sum of squares; MS: Mean sum of squares; F: F-statistic; CV: Coefficient of variation; GM: Grand mean

\section{Acknowledgements}

Authors thank Xiufen Yang and Lihua Guo of the Institute of Plant Protection, Chinese Academy of Agricultural Sciences for their valuable advice on the experimental protocols and for their technical assistance.

\section{Authors' contributions}

AUK, TN, and DQ conceived and designed the experiments. MAG and TN collected the data. GHJ and TA analyzed the data. AUK and TA performed the experiment. AUK, TS, and YAA wrote the paper. DQ critically revised of the manuscript for intellectual content. All authors read and approved the final manuscript.

\section{Funding}

This research was funded by the National Key Research and Development Program of China (2017YFD0200900) and was partially supported by the Graduate School of Chinese Academy of Agricultural Sciences (GSCAAS) for providing the PhD fellowship for this study.

Availability of data and materials

All data and materials are mentioned in the manuscript.

Ethics approval and consent to participate

Not Applicable.

Consent for publication

Not Applicable.

\section{Competing interests}

The authors declare that they have no competing interests.

\section{Author details}

${ }^{1}$ State Key Laboratory for Biology of Plant Diseases and Insect Pests, Institute of Plant Protection, Chinese Academy of Agricultural Sciences, Beijing 100081, People's Republic of China. 'Department of Plant Pathology, Sindh Agriculture University, Tandojam, Sindh 70060, Pakistan. ${ }^{3}$ Punjab Agriculture Department, Pest Warning \& Quality Control of Pesticides, Lahore, Punjab 54000, Pakistan.

Received: 29 January 2020 Accepted: 6 April 2020

Published online: 15 April 2020

\section{References}

Abdel-Raheem MA, Reyad NF, Abdel-Rahman IE, Al-Shuraym L (2016) Evaluation of some isolates of entomopathogenic fungi on some insect pests infesting potato crop in Egypt. Int J Chem Tech Res 9:479-485

Annamalai M, Kaushik HD, Selvaraj K (2016) Bioefficacy of Beauveria bassiana (Balsamo) Vuillemin and Lecanicillium lecanii Zimmerman against Thrips tabaci Lindeman. Proc Natl Acad Sci India Sect B Biol Sci 86:505-511

Ansari MA, Vestergaard S, Tirry L, Moens M (2004) Selection of a highly virulent fungal isolate, Metarhizium anisopliae CLO 53, for controlling Hoplia philanthus. J Invertebr Pathol 85:89-96

Cabanillas HE, Jones WA (2009) Pathogenicity of Isaria sp.(Hypocreales: Clavicipitaceae) against the sweet potato whitefly B biotype, Bemisia tabaci (Hemiptera: Aleyrodidae). Crop Prot 28:333-337

Cuthbertson AGS, Blackburn LF, Northing P et al (2010) Chemical compatibility testing of the entomopathogenic fungus Lecanicillium muscarium to control Bemisia tabaci in glasshouse environment. Int J Environ Sci Technol 7:405409

Dogan YO, Hazir S, Yildiz A et al (2017) Evaluation of entomopathogenic fungi for the control of Tetranychus urticae (Acari: Tetranychidae) and the effect of Metarhizium brunneum on the predatory mites (Acari: Phytoseiidae). Biol Control 111:6-12

Feng MG (1998) Diversity of entomopathogenic fungi as resources useful for microbial control of insect pests. In: Proceedings of the First International 
Symposium on the Geoenvironmental Changes and Biodiversity in the Northeast Asia. pp 16-19

Freed S, Jin F-L, Ren S-X (2011) Phylogenetics of entomopathogenic fungi isolated from the soils of different ecosystems. Pakistan J Zool 43:417-425

Goettel MS, Jaronski ST (1997) Safety and registration of microbial agents for control of grasshoppers and locusts. Mem Entomol Soc Canada 129:83-99

Halimona J, Jankevica L (2011) The influence of Entomophthorales isolates on aphids Aphis fabae and Metopeurum fuscoviride. Latv Entomol 50:55-60

Hanan A, Basit A, Nazir T, Majeed MZ, Qiu D (2020b) Anti-insect activity of a partially purified protein derived from the entomopathogenic fungus Lecanicillium lecanii (Zimmermann) and its putative role in a tomato defense mechanism against green peach aphid. J Inv Pathol 170:107282

Hanan A, Nazir T, Basit A et al (2020a) Potential of Lecanicillium lecanii (Zimm.) as a microbial control agent for green peach aphid, Myzus persicae (Sulzer)(Hemiptera: Aphididae). Pak J Zool 52

Hesketh H, Alderson PG, Pye BJ, Pell JK (2008) The development and multiple uses of a standardised bioassay method to select hypocrealean fungi for biological control of aphids. Biol Control 46:242-255

Horowitz R, Kontsedalov S, Khasdan V et al (2008) The biotypes B and Q of Bemisia tabaci in Israel--distribution, resistance to insecticides and implications for pest management. J Insect Sci 8

Hywel-Jones NL, Gillespie AT (1990) Effect of temperature on spore germination in Metarhizium anisopliae and Beauveria bassiana. Mycol Res 94:389-392

Jackson MA, Dunlap CA, Jaronski ST (2010) Ecological considerations in producing and formulating fungal entomopathogens for use in insect biocontrol. BioControl 55:129-145

Lacey LA, Fransen JJ, Carruthers R (1996) Global distribution of a naturally occurring fungi of Bemisia, their biologies and use as biological control agents. Bemisia 1995, Taxon Biol damage, Control Manag

Majeed MZ, Fiaz M, Ma CS, Afzal M (2017) Entomopathogenicity of three muscardine fungi, Beauveria bassiana, Isaria fumosorosea and Metarhizium anisopliae, against the Asian citrus psyllid, Diaphorina citri Kuwayama (Hemiptera: Psyllidae). Egypt J Biol Pest Control 27

Maniania NK (1991) Susceptibility of Chilo partellus Swinhoe (Lep., Pyralidae) eggs to entomopathogenic hyphomycetes. J Appl Entomol 112:53-58

Mora MAE, Castilho AMC, Fraga ME (2017) Classification and infection mechanism of entomopathogenic fungi. Arq Inst Biol (Sao Paulo) 84

Nazir T, Basit A, Hanan A et al (2019) In vitro pathogenicity of some entomopathogenic fungal strains against green peach aphid Myzus persicae (Homoptera: Aphididae). Agronomy 9:7

Oliveira MRV, Henneberry TJE, Anderson P (2001) History, current status, and collaborative research projects for Bemisia tabaci. Crop Prot 20:709-723

Sato H (1993) Effect of temperature on mycelial growth of three muscardine fungi. Trans 44th Meet Kanto Branch Jpn For Soc, 1993 103-104

Shah PA, Goettel MS (1999) Directory of microbial control products and services. Microb Control Div Soc Invertebr Pathol Gainesville, FL 31

Wang Z, Yao M, Wu Y (2009) Cross-resistance, inheritance and biochemical mechanisms of imidacloprid resistance in B-biotype Bemisia tabaci. Pest Manag Sci Former Pestic Sci 65:1189-1194

Wraight SP, Carruthers RI, Jaronski ST et al (2000) Evaluation of the entomopathogenic fungi Beauveria bassiana and Paecilomyces fumosoroseus for microbial control of the silverleaf whitefly, Bemisia argentifolii. Biol Control 17:203-217

Wraight SP, Inglis GD, Goettel MS (2007) Fungi. Field Manual of Techniques in Invertebrate Pathology.(ed. Lacey, LA, \& Kaya, HK), Chapter IV-pp. 223-248

Yun H-G, Kim D-J, Gwak W-S et al (2017) Entomopathogenic fungi as dual control agents against both the pest Myzus persicae and phytopathogen Botrytis cinerea. Mycobiology 45:192-198

Zaki FN (1998) Efficiency of the entomopathogenic fungus, Beauveria bassiana (Bals), against Aphis crassivora Koch and Bemesia tabaci, Gennandius. J Appl Entomol 122:397-399

Zimmermann G (2007) Review on safety of the entomopathogenic fungi Beauveria bassiana and Beauveria brongniartii. Biocontrol Sci Technol 17:553596

\section{Publisher's Note}

Springer Nature remains neutral with regard to jurisdictional claims in published maps and institutional affiliations.

\section{Submit your manuscript to a SpringerOpen ${ }^{\circ}$ journal and benefit from:}

- Convenient online submission

- Rigorous peer review

- Open access: articles freely available online

High visibility within the field

- Retaining the copyright to your article

Submit your next manuscript at $\boldsymbol{\nabla}$ springeropen.com 